\title{
UTILIZAÇÃO DE RESÍDUOS DE ENSAIOS DE COMBUSTÍVEIS PARA A LAVAGEM DE FRASCOS DE COLETA.
}

\author{
K. W. L. ROSSITER ${ }^{1}$, I. M. de MELO ${ }^{2}$ E I. E. de VASCONCELOS ${ }^{3}$ \\ ${ }^{1}$ Universidade Federal de Pernambuco, Departamento de Engenharia Química. \\ ${ }^{2}$ Universidade Federal de Pernambuco, Departamento de Engenharia Química. \\ ${ }^{3}$ Universidade Federal de Pernambuco, Departamento de Engenharia Química. \\ E-mail para contato: karinawlr@hotmail.com
}

\begin{abstract}
RESUMO - O Laboratório de Ensaios de Combustíveis (LAC) é acreditado pelo INMETRO para realizar o monitoramento dos combustíveis nos estados de PE, AL e SE. Os combustíveis são coletados em frascos de polietileno que são reutilizados, após lavados com o combustível que sobra dos ensaios. O LAC elaborou um estudo sobre um novo procedimento de lavagem dos frascos, utilizando os resíduos gerados em alguns ensaios, em substituição ao combustível puro. Para cada ensaio foi realizada a caracterização e quantificação dos resíduos gerados, separando os de composição similar. O novo procedimento foi testado e sua eficácia foi avaliada através de um teste visual qualitativo e um estudo analítico considerando o ensaio de massa específica. Este método reduziu o consumo em cerca de $80 \mathrm{~L}$ de gasolina e $135 \mathrm{~L}$ de álcool na lavagem mensal dos frascos, propiciando uma minimização dos resíduos gerados e uma maior disponibilidade de combustível puro que é utilizado internamente ou doado a instituições filantrópicas.
\end{abstract}

\section{INTRODUÇÃO}

Os resíduos gerados em laboratórios de análises químicas, apesar de quantitativamente insignificantes quando relacionados aos gerados no setor produtivo, devem ser gerenciados de forma a minimizar seus impactos para os colaboradores, sociedade e para o meio ambiente ( JARDIM, 2001).

O Laboratório de Combustíveis da UFPE (LAC) é um dos integrantes, dentre as 23 instituições e centro de pesquisas do Programa de Monitoramento da Qualidade de Combustíveis (PMQC) da Agência Nacional de Petróleo (ANP), sendo responsável pelos estados de Pernambuco, Alagoas e Sergipe. As três matrizes coletadas pelo laboratório são: Etanol, Gasolina e Diesel. Esses combustíveis são coletados em garrafas de polietileno de 1 litro, que após lavagem são reutilizadas em novas coletas. Após a conclusão das análises, o restante dos combustíveis é utilizado na lavagem dos frascos de coleta e seu excedente é utilizado na frota interna ou doado a instituições filantrópicas. 
A quantidade de resíduos gerados através da lavagem dessas garrafas, bem como o resíduo resultante dos próprios ensaios é uma preocupação constante para LAC e motivou a elaboração de um plano de gerenciamento de resíduos, base para a realização deste trabalho.

Esta pesquisa teve como objetivo estabelecer uma nova metodologia para lavagem das garrafas de coleta de gasolina e diesel, através do reaproveitamento dos resíduos das análises, minimizando assim os gerados e maximizando a utilização dos combustíveis puros. As tampas utilizadas para a vedação dos frascos foram excluídas destes estudos, pois não são reutilizadas em função dos lacres e também as garrafas utilizadas para coleta de etanol, pois estas são apenas secadas para sua reutilização, ou seja não são submetidas aos processos de lavagem.

\section{GERENCIAMENTO DE RESÍDUOS}

Produzidos em todos os estágios das atividades humanas, os resíduos, em termos tanto de composição como de volume, variam em função das práticas de consumo e dos métodos de produção. As principais preocupações estão voltadas para as repercussões que podem ter sobre a saúde humana e sobre o meio ambiente (solo, água, ar e paisagens). Os resíduos perigosos, produzidos sobre tudo pelas indústrias, são particularmente preocupantes, pois, quando incorretamente gerenciados, tornam-se uma grave ameaça ao meio ambiente ( CAVALCANTI, 1998).

Baseado no compromisso em relação à proteção à saúde da população e dos seus colaboradores, aos riscos potenciais oriundos da manipulação, tratamento e disposição final inadequada dos seus resíduos o LAC elaborou um Programa de Gerenciamento de Resíduo (PGR). Este programa teve como objetivo definir os procedimentos adequados para segregação, identificação, tratamento e destino dos resíduos, englobando ainda o estudo sobre a substituição de métodos de análise e/ou reagentes como forma de minimizar o volume e /ou a toxidade dos resíduos gerados.

A abordagem de prevenir, minimizar e tratar (3R's) os resíduos, bem como a "química verde" nortearam a elaboração do PGR. A química verde baseia-se na utilização de técnicas químicas e metodologias que reduzem ou eliminam o uso de solventes e reagentes ou geração de produtos e subprodutos tóxicos, que são nocivos à saúde humana ou ao ambiente ( PRADO,2003).

\section{METODOLOGIA}


Esta pesquisa foi elaborada em seis etapas. Inicialmente para cada análise realizada nos combustíveis foi estudada a caracterização e quantificação dos resíduos gerados. Em seguida foi criada uma codificação para todos os resíduos, independente da utilização ou não na lavagem, para que aqueles que apresentassem similaridade na composição química fossem agregados. Posteriormente, foi elaborado um novo procedimento de lavagem, utilizando alguns resíduos oriundos das análises. A seguir foi realizado um balanço entre a quantidade de resíduo gerada e a utilizada na substituição dos combustíveis puros nas lavagens, avaliando sua viabilidade ou não. Para validar a qualidade da lavagem foi realizado um teste cego com os supervisores do LAC comparando garrafas lavadas pelo método antigo e pelo proposto, bem como realizado o ensaio de massa especifica em amostras de diesel e gasolina para verificar se o novo procedimento alteraria o resultado do ensaio. Em seguida, foi realizado um estudo de tempo para verificar se o novo procedimento alteraria de forma significativa nas atividades dos analistas. Por fim, foi calculada a estimativa da economia de combustível puro e criada toda a estrutura para que o novo procedimento pudesse ser implantado, incluindo o treinamento dos analistas.

\section{RESULTADOS E DISCUSSÃO}

\subsection{Caracterização dos Resíduos Gerados nas Análises.}

Os ensaios, métodos de análise e especificação para cada combustível são determinados por Regulamentações da ANP. A Resolução ANP n. 40, de 25. 10. 2013 determina os ensaios para a gasolina, a Resolução ANP n. 40 Resolução ANP n. 50, de 23.12.2013 relaciona- se ao diesel e a Resolução ANP n. 07 de 09.02.2011 se refere ao etanol.

Em cada matriz: gasolina, diesel e álcool, foram evidenciados quais os resíduos gerados em cada análise, para estudar a viabilidade de sua utilização nas lavagens dos frascos de coleta. Vale salientar que em grande parte dos procedimentos dos ensaios, se faz necessário uma lavagem das vidrarias e ou equipamento utilizados, sendo esta etapa também considerada como resíduo gerado. Os resultados deste levantamento são apresentados na Tabela 1, onde consta ainda a informação de qual a cor ou simbologia foi adotada para o resíduo descartado na bombona: 
Tabela 1 - Ensaios e resíduos gerados

\begin{tabular}{|c|c|c|c|}
\hline Ensaio & Composição do Resíduo & Caracterização & Cor ou Símbolo \\
\hline \multicolumn{4}{|c|}{ ANÁLISES GASOLINA } \\
\hline \multirow{3}{*}{ Destilação } & Gasolina Destilada & Gasolina pura & \\
\hline & Etanol + Gasolina (traços) & Lavagem 02 (LAV2) & \\
\hline & Residuo do balão & a ser descartado & \\
\hline \multirow{2}{*}{ Teor de Álcool } & Etanol + Gasolina (traços) & Lavagem 02 (LAV2) & \\
\hline & Gasolina + Etanol + solução de $\mathrm{NaCl}$ & a ser tratado & \\
\hline \multirow[b]{2}{*}{ Massa Específica } & Gasolina & Gasolina pura & \\
\hline & Gasolina + Etanol+Èter + Acetona & a ser descartado & \\
\hline \multirow{3}{*}{ Teor de Benzeno } & Gasolina & Gasolina pura & \\
\hline & Etanol + Gasolina (traços) & Lavagem 02 (LAV2) & \\
\hline & éter de petróleo + gasolina & a ser descartado & \\
\hline Aspecto & Gasolina & Gasolina pura & \\
\hline \multicolumn{4}{|c|}{ ANÁLISES DIESEL } \\
\hline \multirow{3}{*}{ Destilação } & Diesel Destilado & Diesel puro & \\
\hline & Gasolina + Diesel (traços) & Lavagem 01 (LAV01) & \\
\hline & Residuo do balão & a ser descartado & \\
\hline \multirow[b]{2}{*}{ Massa Específica } & Diesel & Diesel puro & \\
\hline & Diesel+ Gasolina +Etanol+Éter + Acetona & a ser descartado & \\
\hline \multirow{3}{*}{ Fulgor } & Diesel & Diesel puro & \\
\hline & Gasolina + Diesel (traços) & Lavagem 01( LAV 1) & \\
\hline & Etanol + Gasolina (traços) & Lavagem 02 (LAV2) & \\
\hline \multirow{3}{*}{ Teor de enxofre } & Diesel & Diesel Puro & \\
\hline & Gasolina + Diesel (traços) & Lavagem 01 (LAV01) & \\
\hline & Etanol + Gasolina (traços) & Lavagem 02 (LAV2) & \\
\hline \multirow{2}{*}{ Cor } & Diesel & Combustível puro & \\
\hline & Gasolina +Etanol + Diesel & a ser descartado & \\
\hline Aspecto & Diesel & Combustível puro & \\
\hline \multicolumn{4}{|c|}{ ANÁLISES ETANOL } \\
\hline \multirow{2}{*}{$\begin{array}{c}\text { Teor de } \\
\text { Hidrocarbenato }\end{array}$} & Etanol + Gasolina (traços) & Lavagem 02 (LAV2) & \\
\hline & Gasolina + Etanol + solução de $\mathrm{NaCl}$ & a ser tratado & \\
\hline $\mathrm{pH}$ & Etanol & Etanol puro & \\
\hline Condutividade & Etanol & Etanol puro & \\
\hline Aspecto & Etanol & Etanol puro & \\
\hline \multirow{2}{*}{ Massa Específica } & Etanol & Etanol puro & \\
\hline & Etanol +Éter de Petróleo+Cetona & a ser descartado & \\
\hline
\end{tabular}


A substituição dos combustíveis puros por resíduos nas lavagens dos frascos de coletar de diesel e gasolina se baseariam em:

Gasolina pura= substituída pelo LAV 01( gasolina com traços de diesel).

* Álcool puro = substituído pelo LAV 2( álcool com traços de gasolina).

Após o conhecimento dos resíduos gerados e sua composição era necessária a quantificação dos mesmos, para verificar a viabilidade da substituição proposta.

\subsection{Quantificação dos Resíduos Gerados}

O levantamento dos resíduos gerados foi realizado para todos os ensaios. Contudo apresentaremos neste trabalho apenas os dados referentes aos resíduos LAV 01 e LAV 02, pois serão estes utilizados na proposta do novo procedimento.

Os resultados encontram-se na Tabela 2 abaixo:

Tabela 2 - Volume mensal gerado por matriz

\begin{tabular}{|c|c|c|c|c|}
\hline \multicolumn{5}{|c|}{ LAV - 01 ( Gasolina + traços de diesel) } \\
\hline Matriz & Ensaio & $\begin{array}{c}\text { Volume } \\
\text { gerado por } \\
\text { análise }(\mathrm{ml}) \\
\end{array}$ & $\begin{array}{l}\text { Quantidade } \\
\text { de análises } \\
\text { por mês }\end{array}$ & $\begin{array}{l}\text { Volume } \\
\text { gerado por } \\
\text { mês (L). }\end{array}$ \\
\hline \multirow{3}{*}{ Diesel } & Destilação & 52 & 950 & 49,40 \\
\hline & Fulgor & 15 & 950 & 14,25 \\
\hline & $\begin{array}{l}\text { Teor de } \\
\text { enxofre }\end{array}$ & 12 & 950 & 11,40 \\
\hline \multicolumn{4}{|c|}{ Total gerado de LAV - 01( litros/mês) } & 75,05 \\
\hline \multicolumn{5}{|c|}{\begin{tabular}{ll|l|l} 
LAV - 02 ( Etanol + traços de & & \\
gasolina) & & \\
\end{tabular}} \\
\hline \multirow[b]{3}{*}{ Gasolina } & Destilação & 53 & 980 & 51,94 \\
\hline & Teor de Álcool & 34 & 980 & 33,32 \\
\hline & $\begin{array}{l}\text { Teor de } \\
\text { Benzeno }\end{array}$ & 11 & 980 & 10,78 \\
\hline \multirow[b]{2}{*}{ Diesel } & Fulgor & 16 & 950 & 15,20 \\
\hline & $\begin{array}{l}\text { Teor de } \\
\text { Enxofre }\end{array}$ & 11 & 950 & 10,45 \\
\hline Etanol & $\begin{array}{l}\text { Teor de } \\
\text { Hidrocarbonat } \\
\text { o }\end{array}$ & 33 & 450 & 14,85 \\
\hline \multicolumn{4}{|c|}{ Total gerado de LAV-02 ( litros/mês) } & 136,54 \\
\hline
\end{tabular}




\subsection{Procedimento de Lavagem e Nova Proposta}

O procedimento estabelecido para a lavagem dos frascos de gasolina, baseado no uso de combustíveis remanescentes das análises, é apresentado conforme mostra a Figura 1:

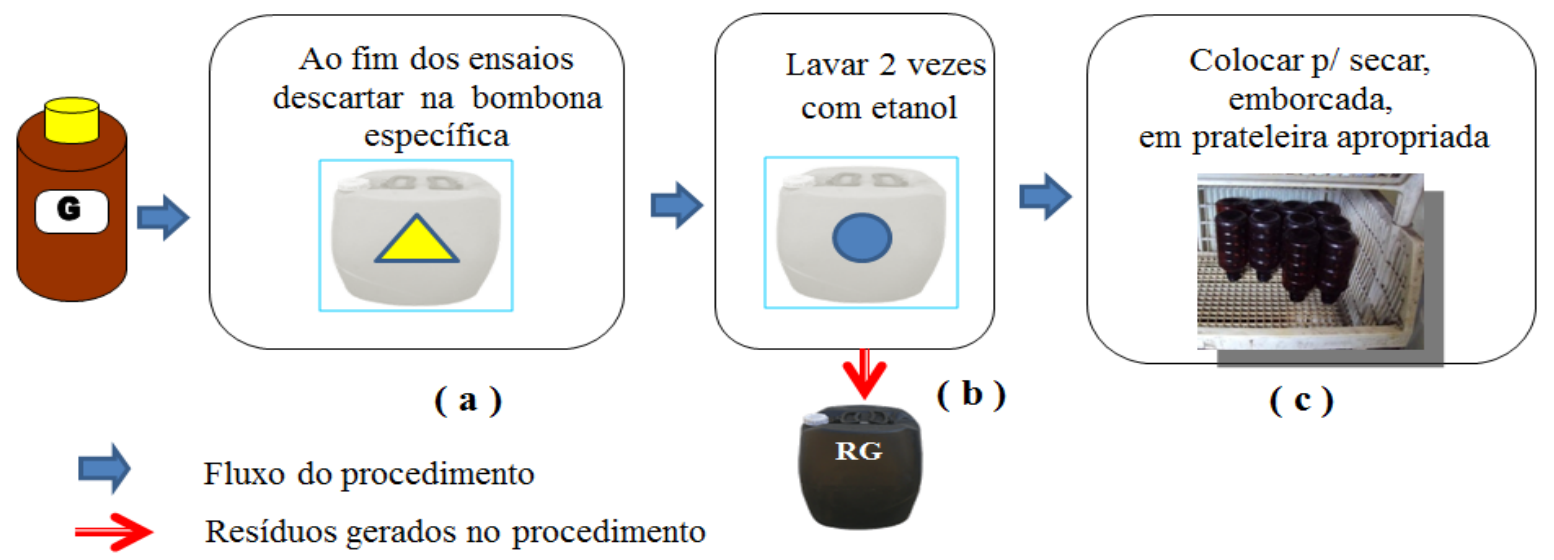

Figura 1 - Lavagem dos frascos de gasolina

Para conseguir retirar toda a gasolina é necessário lavar o frasco duas vezes com etanol, sendo gasto um volume médio de $70 \mathrm{ml}$ na lavagem. Para uma média de 980 amostras por mês isto significa um consumo médio de 68,60 litros de etanol puro, destinado apenas para lavagem. A proposta do novo procedimento consiste em substituir o uso do etanol pelo resíduo LAV2 gerado em alguns ensaios, cuja composição é etanol com traços de gasolina.

Para os frascos de coleta de diesel o procedimento é descrito na a Figura 2 abaixo:

(a)

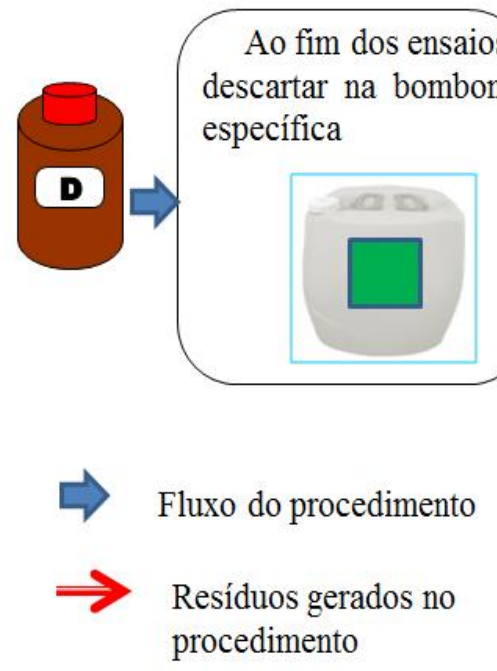

(b)

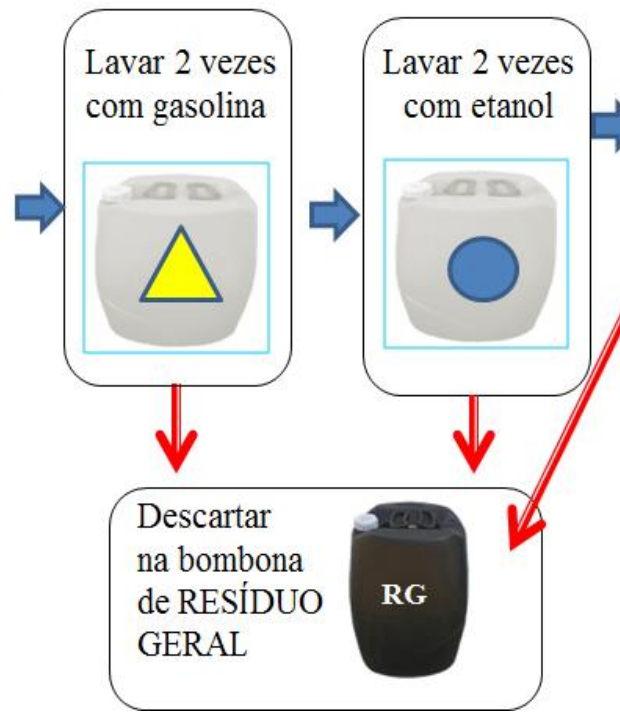

(d) 
Após o descarte do restante de diesel(a) , o frasco é lavado duas lavagem com gasolina(b) e duas com etanol(c) ambos puro, depois prossegue com uma lavagem com detergente e enxágue abundante com água (d) e por fim é rinsado com etanol puro(e), o qual tem a função de auxiliar na secagem das garrafas. Nas etapas (b) e (c) o consumo médio de combustivel puro é de $35 \mathrm{ml}$ por etapa de lavagem. Tendo como média 950 coletas por mês, e que na etapa (b) e (c) ocorrem lavagens duplas,isto significa um consumo de 66,5 litros de gasolina e 66,5 litros de etanol gastos na lavagem dos frascos de coleta de diesel.

No novo procedimento as alterações propostas foram: na etapa (b) a gasolina seria subsitituida pelo LAV1 e o etanol utilizado na etapa (d) seria substituído pelo LAV 02 incorporado ao LAV2. Na etapa (c), a substituição do etanol pelo LAV2.

Os teste do procedimento proposto foram realizados e seus resultados avaliados. Vale ressaltar que todos os combustíveis puros que são gerados como saída dos ensaios já eram aproveitados na lavagem dos frascos de coleta no procedimento anterior.

\subsection{Avaliação Técnica: Quantitativa e Qualitativa}

Após o levantamento das quantidades geradas e consumidas nas lavagens dos frascos foi possível realizar o balanço dos volumes, conforme valores da Tabela 3:

Tabela 3 - Consumo x produção de resíduos

\begin{tabular}{|l|c|c|c|c|c|}
\hline \multirow{2}{*}{ Resíduo } & \multirow{2}{*}{$\begin{array}{c}\text { Gerado nos } \\
\text { ensaios } \\
\text { (litros/mês) }\end{array}$} & \multicolumn{3}{|c|}{$\begin{array}{c}\text { Consumido na lavagem dos frascos } \\
\text { (litros/mês) }\end{array}$} & $\begin{array}{c}\text { Saldo (gerado } \\
\text { - consumido) } \\
\text { (litros/mês) }\end{array}$ \\
\cline { 3 - 5 } & Gasolina & Diesel & Total & 8,55 \\
\hline LAV 01 & 75,05 & 0 & 66,50 & 66,50 & 1,44 \\
\hline
\end{tabular}

Ou seja, do aspecto quantitativo os volumes gerados nos ensaios são suficientes para as substituições propostas no procedimento, pois ainda há uma pequena sobra de LAV $01 \mathrm{e}$ LAV 02. Esta sobra seria incorporada ao resíduo geral. Contudo foi fundamental também avaliar se o método proposto iria realmente promover uma boa qualidade de limpeza nas garrafas, bem como não seria uma fonte de contaminação influenciando nos resultados dos ensaios.

A eficácia da lavagem foi atestada, a partir de um teste cego, comparando os aspectos visuais e olfativos entre os frascos lavados pelo método antigo e pelo método proposto, realizados com os supervisores do LAC.

Para a validação final do método proposto também foi realizado um estudo com um ensaio físico-químico: a massa específica, que expressa a relação massa/volume da amostra, sendo este ensaio sensível a qualquer sinal de contaminação. Este ensaio é realizado para a gasolina e para o diesel conforme a norma ABNT NBR 14065 -Destilados de Petróleo e óleos viscosos - Determinação da massa específica e da densidade relativa pelo densímetro digital, e especifica uma repetitividade de 0,45 para gasolina e 0,16 para o diesel. 
Duas amostras de gasolina e diesel, coletadas em frascos lavados pelo método antigo e pelo método proposto, foram analisadas e os resultados constam na Tabela 4:

Tabela 4 - Resultado do estudo analítico- ensaio de massa especifica

\begin{tabular}{|c|c|c|c|c|}
\hline Amostra & Frasco & $\begin{array}{l}\text { Resultado } \\
\left(\mathrm{kg} / \mathrm{m}^{3}\right)\end{array}$ & $\begin{array}{l}\text { Repetitividade } \\
\text { da análise }\end{array}$ & Desvio padrão \\
\hline \multirow[b]{2}{*}{ Diesel 1} & Método antigo & 831,5 & \multirow[t]{2}{*}{0,40} & \multirow[t]{2}{*}{0,28} \\
\hline & Método proposto & 831,1 & & \\
\hline \multirow[b]{2}{*}{ Diesel 2} & Método antigo & 830,1 & \multirow[t]{2}{*}{0,30} & \multirow[t]{2}{*}{0,21} \\
\hline & Método proposto & 829,8 & & \\
\hline \multirow[b]{2}{*}{ Gasolina 1} & Método antigo & 745,7 & \multirow[t]{2}{*}{0,10} & \multirow[t]{2}{*}{0,07} \\
\hline & Método proposto & 745,6 & & \\
\hline \multirow[b]{2}{*}{ Gasolina 2} & Método antigo & 745,1 & \multirow[t]{2}{*}{0,10} & \multirow[t]{2}{*}{0,07} \\
\hline & Método proposto & 745,0 & & \\
\hline
\end{tabular}

Observando a tabela 4 foi verificado que a diferença dos procedimentos de lavagem não alterou os resultados do ensaio de massa específica, que se mantiveram dentro tanto da repetitividade da norma quanto do desvio padrão especificado.

Por fim, foi realizado um estudo sobre o impacto referente ao tempo nas atividades dos analistas, com este novo procedimento de lavagem. Após os devidos treinamentos, foi monitorado durante uma semana o tempo gasto na separação destes resíduos dos ensaios e evidenciou- se que o mesmo não alterou significativamente as atividades dos analistas, não havendo acréscimo no tempo de realização da atividade.

\section{CONCLUSÕES}

Diante dos resultados apresentados conclui-se que o objetivo da pesquisa foi alcançado, pois esta nova proposta de procedimento de lavagem se mostrou válida para a minimização dos resíduos gerados, bem como para uma utilização mais nobre dos combustíveis puros remanescentes dos ensaios. As vantagens desta nova prática foram: minimização dos resíduos, reuso e reaproveitamento de resíduos na lavagem de frascos e vidrarias; economia de recursos; redução de impactos ambientais; tratamento dos resíduos no próprio laboratório e promoção da educação ambiental no LAC.

\section{REFERENCIAS}

CAVALCANTI, J. E. A década de 90 é dos resíduos sólidos. Revista Saneamento Ambiental - n ${ }^{\circ}$ 54, p. 16-24, nov./dez. 1998.

JARDIM, W.F. Gerenciamento de Resíduo Químico. São Paulo: UNICAMP. 2001. Disponível em :http://lqa.iqm.unicamp.br/pdf/LivroCap11.PDF. Acesso em 15 mar.2014.

PRADO. A. G. S. Química verde, os desafios da química do novo milênio. Quim. Nova, v.l. 26, No. 5, p. 738-744, 2003. 